\title{
An Absorbing Improvement for Space Infection Decompression: A Novel Drainage Device
}

\author{
Ansha Bharath (D) \\ Srikanth SC Madabhushi ${ }^{2}$ \\ 'Government Dental College and \\ Research Institute, Bangalore, India; \\ ${ }^{2}$ University of Colorado, Boulder, \\ CO, USA
}

\begin{abstract}
Introduction: Infection of the facial spaces and the associated exudate can often necessitate surgical intervention. Whilst traditional decompression methodologies have reduced the mortality rate from complications such as Ludwig's Angina, there has been relatively little innovation in the procedure to minimize treatment times and patient distress. Negative pressure wound therapy, which can yield improvements to treatment time, wound healing and patient experience, has gained traction in abscess treatments in other parts of the body but seen limited adoption in maxillofacial surgeries.
\end{abstract}

Methods: A focused literature review explores the existing treatment methodologies for infected facial space decompression and identifies obstacles to implementing negative pressure wound therapy in maxillofacial surgeries. A novel drainage tool, which features a sleeved sponge over a perforated drainage tube, is proposed. Virtual prototyping and structural analyses of the novel drainage device including a parametric design study are presented.

Results: The parametric study validates the proposed tool's biocompatibility in terms of overall flexural and axial stiffness between the tool and complex structures in the head and neck. Ultimately, this work presents a necessary first step in the development of specialized drainage tools to promote the adoption of negative pressure wound therapy for infections of facial spaces. Keywords: space decompression, facial space infection, vacuum-assisted drainage, negative pressure wound therapy, drainage devices, virtual prototyping

\section{Introduction}

Infection of the facial spaces and the associated exudate poses both a physiological and a psychological risk. Edemata of the neck and face can impede food intake and affect patients' speech and confidence. Further, complications such as Ludwig's angina in the submandibular and sublingual spaces can lead to life-threatening airway compromise. Such conditions are disproportionately prevalent in developing nations where access to antibiotics and appropriate early medical interventions can be lacking. Current space infection decompression typically involves passive drains that are left sutured to the patient for between 2 and 7 days, require frequent flushing of the site with antibiotics and often necessitate manual compression of the abscess to drive the thicker exudates out of the area. ${ }^{1}$

Vacuum assisted drainage has been demonstrated to provide several benefits over passive drains, including reduced treatment times, superior wound healing by promoting granulation tissue formation and lower risk of life-threatening complications. ${ }^{2}$ However, Fleischmann et $\mathrm{al}^{3}$ and Rosenthal et $\mathrm{al}^{4}$ describe how the adoption of vacuum assisted drainage for maxillofacial applications has been relatively limited. Broadly, a lack of biocompatibility between the vacuum assisted drainage tool and the complex 
structures of the head and neck has been identified as a key driver for the limited adoption of vacuum assisted drainage in these applications. In this context, biocompatibility refers to an appropriate strength and stiffness of the drainage tool to be used in the drainage procedure.

In this paper, a novel drainage tool design is proposed, focused on addressing the existing lack of a tool and procedure to use vacuum assisted drainage for infections of the facial spaces. In recognition of the importance of biocompatibility of the tool design in terms of its overall stiffness, a design study featuring virtual prototyping of variants of the tool dimensions is presented. Ultimately, the virtual prototyping results are used to validate the proposed design concept.

\section{Review of Literature}

In order to propose and investigate an improved design tool for facial space infection decompression, literature relating to facial space infections requiring surgical intervention, the existing treatment procedure, the general benefits of vacuum assisted drainage and the underlying reasons for its limited adoption to maxillofacial applications are explored.

\section{Infections of the Facial Spaces}

Etiologically speaking, infection of the mandibular molars can account for the majority of facial space infections, also presenting in conjunction with compound fractures of the mandible or laceration of the floor of the mouth. ${ }^{5}$ More recently and in agreement with previous studies, Umeda et $\mathrm{al}^{6}$ report that $66.6 \%$ of head and neck infections with odontogenic sources are from the mandibular molars, with Zamiri et $\mathrm{al}^{7}$ reporting from their study that submandibular space infection had the highest occurrence of $32 \%$ followed by the masseteric space with $22 \%$. Similar findings were recently reported by Eshghpour et al. ${ }^{8}$

In cases where localisation of the infection does not occur, the infection can spread rapidly throughout the fascial planes of the head and neck. Bilateral infection of the submandibular, submental and sublingual spaces may also lead to complications such as Ludwig's Angina that can result in life threatening airway compromise. ${ }^{5}$ Once established in the submandibular space, infections can also spread superiorly leading to infections of the anterior neck, the pharyngomaxillary space and ultimately leading to a brain abscess, cavernous sinus thrombosis and meningitis or spread inferiorly to retropharynx, superior mediastinum or the pericardium. ${ }^{7}$
Overall, Lemonick ${ }^{9}$ describes that surgical interventions are commonly practiced for cases when there is evidence of a suppurative infection, accumulation of fluid and/or softtissue air supported by clinical fluctuance, positive purulent needle aspirate or ineffective antibiotic therapy.

\section{Treatment Modalities}

\section{Existing Treatment of Infected Facial Spaces}

Hilton's method of incision and drainage for abscesses, as summarized by $\mathrm{Ahmad}^{10}$ for example, typically begins with an incision on the most dependent or prominent part of the swelling. Blunt instruments, such as a hemostat or sinus forceps, are introduced to the wound cavity. The instrument is then withdrawn with opened beaks to break loculi of pus. The abscess is next "de-roofed" surgically by either extending the incisions or excising another part of the skin. In areas of aesthetic concern, incisions are planned along normal skin creases or langer lines. Alternatively, in areas where it is prudent, incisions are planned along the line of underlying vessels.

Broadly, the subsequent drainage methodologies may be distinguished by the use of stiffer, rubber drainage lines inserted into the abscess versus softer gauze strips, potentially dipped in desloughing solutions,${ }^{10}$ that are packed into and around the abscess. Primarily, access to the abscess dictates the choice of methodology. Specific to abscesses in the head and neck, stiffer rubber drainage lines are typically used. A historical example of an incision and drainage of a facial space infection is illustrated in Figure 1.

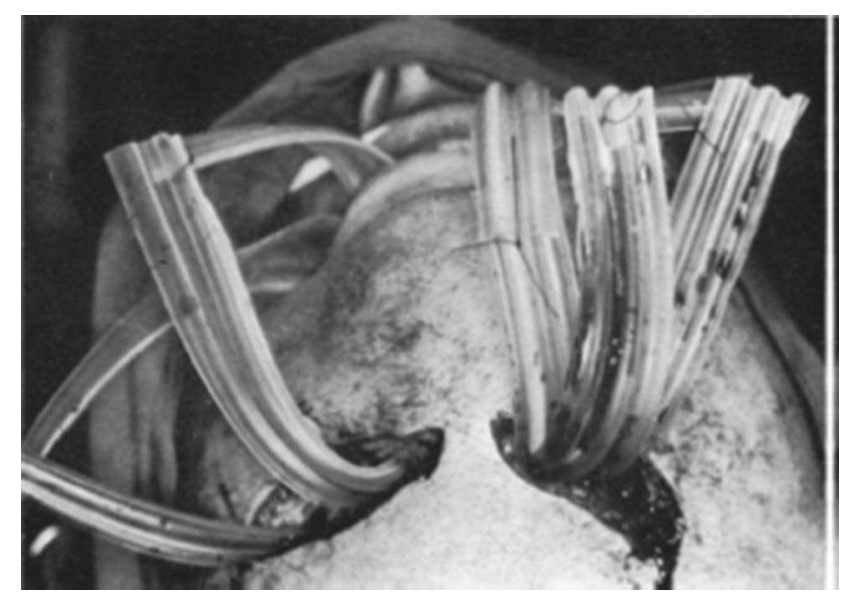

Figure I Photo showing historical abscess drainage of an infection in a facial space. Reprinted from $\mathrm{Br} J$ Oral Surg. 13(2), Holland CS. The management of Ludwig's angina. 153-159, Copyright (1975), with permission from Elsevier. ${ }^{5}$ 
In the case of passive drainage, the purulent material will exit the infected site driven by the pressure difference (strictly the potential or total head difference) between the abscess and end of the drainage tube and/or capillary action. ${ }^{11}$ Drains are held in place using multiple sutures and regular dressing changes ensure patency of the drain and allow for flushing of the abscess with antibiotics. Further, periodic manipulation of the abscess, via manual expression or probing using blunt forceps may be necessary to complete the procedure. ${ }^{12}$

Overall, the use of passive drainage with relatively stiff drainage lines for facial space infections may have several disadvantages. Passive drainage of these odontogenic sites can be associated with long hospital stays, for example the study by Zamiri et $\mathrm{al}^{7}$ reports a mean stay of 5.8 days with the least duration of 48 hours, in general agreement with a previous study by Peters et al. ${ }^{13}$ More recently, Vithal et $\mathrm{al}^{14}$ report an average duration of 14 days, with a range of 10 to 25 days. The use of stiffer drainage tubes can also be unsuitable for navigating the complex structures of the face and neck, an issue of biocompatibility of the drainage tools which will be discussed further in the following sections.

\section{Negative Pressure Wound Therapy}

The historical context of active drainage or negative pressure wound therapy is summarized by Miller. ${ }^{15}$ Miller $^{15}$ notes the findings from historians about the recorded use of direct mouth suction in the Roman era. Such practices continued with records in the 18th century by a French Surgeon Dr. Dominique Anel noting "lip service" performed by "wound suckers" may have been distasteful but effective in the treatment of injured soldiers. Dr. Anel subsequently developed a suction syringe that would also be used to drain abscesses.

Miller ${ }^{15}$ goes on to describe the development of the cupping method and the development of the "Glass Leech" in 1821 by British physician Dr Francis Fox. The tool performed similarly to its namesake, clinging to the wound site under suction and would be developed with time to include tubing and a bulb to further refine the accelerated drainage of purulent material.

In recent decades, the use of incisional negative pressure wound therapy characteristically features polyurethane foam as part of the wound dressing and a mechanical vacuum. Standardization of the drainage tools and suctions has helped lead to the use of the technique to manage high risk surgical site wounds. ${ }^{16}$ Negative pressure wound therapy has also been reportedly used in a diverse array of specialties, including general and plastic surgery and orthopedics. ${ }^{17}$ Advantages associated with the method include accelerated drainage rates and reduced rate of infection compared to a pressure dressing. ${ }^{18}$ Further, Argenta ${ }^{19}$ and Gallo ${ }^{20}$ note that negative pressure wound therapy can also stimulate the formation of granulation tissue and improve closure of the subcutaneous layers. Overall, patient comfort, decreased hospitalization time and decreased workload for the medical team can be achieved. ${ }^{21,22}$

An example of an existing drainage tool used with negative pressure wound therapy is shown in Figure 2. In conjunction with an endoscope, Arezzo et $\mathrm{al}^{23}$ described the use of such a tool to drain rectal abscesses. The tool shown in Figure 2 features an open cell, polyurethane sponge attached to the end of the drainage tube. The sponge is initially sized to the approximate volume of the abscess and can be resized during the procedure as the abscess lining shrinks and/or collapses. From a design perspective, a soft sponge at the end of the drainage tube is suited to infections where the spatial volume drained is expected to significantly reduce at the completion of the procedure. Further, as the "head" of such drainage tools is very soft it cannot readily navigate stiffer biological structures without the aid of a larger and stiffer sleeved tube.

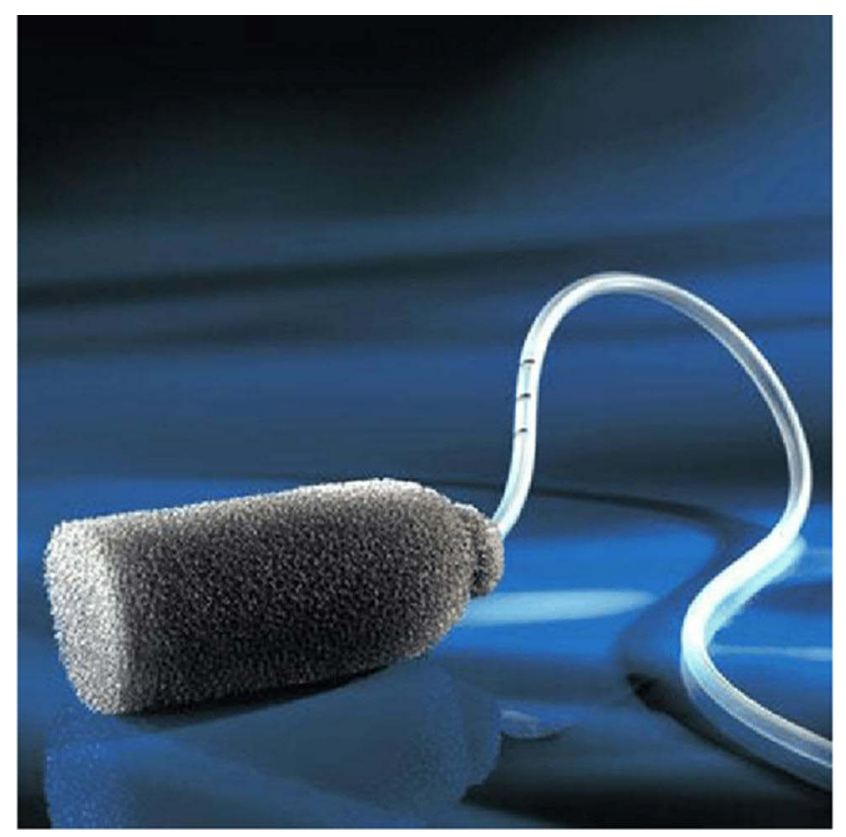

Figure 2 Example of an existing drainage tool ("Endo-SPONGE") used with negative pressure wound therapy. Reprinted by permission from Springer: Springer Nature, Tech Coloproctol, 14(3):279-28I, Endoluminal vacuum therapy for anastomotic leaks after rectal surgery, Arezzo A, Miegge A, Garbarini A, Morino M, Copyright $2010 .^{23}$ 
Negative Pressure Wound Therapy for Facial Spaces Despite the growing prevalence and evidence of the benefits of negative pressure wound therapy, Umezawa et $\mathrm{al}^{2}$ note that the technique has seen limited application in Oral and Maxillofacial surgeries. Whilst Schuster et $\mathrm{al}^{24}$ is an early reported example of the technique applied to maxillofacial surgery, Cao et $\mathrm{al}^{25}$ summarize two key challenges for deep facial space infections which may have limited its subsequent adoption. Firstly, obtaining an airtight seal and/or maintaining sufficient suction at the distal end of the drainage tube and secondly the depth to which the packing material, such as a foam, can be driven. In the latter case, a trade-off in insertion depth between maintaining suction and avoiding plugging of the foam/growth of healing tissue into the soft sponge may exist. ${ }^{26}$

Umezawa et $\mathrm{al}^{2}$ and Coa et $\mathrm{al}^{25}$ present adaptations to existing drainage tools to better meet the maxillofacial surgical needs. For example, Umezawa et $\mathrm{al}^{2}$ describe a novel technique using penrose drains and negative pressure wound therapy to treat complications following several reconstructive surgeries. It is clear that such a modified technique can only be applied where the penrose drain, which does not readily hold its shape, can easily access the infected space. Similarly, Coa et $\mathrm{al}^{25}$ document the use of side perforated latex drainage tubes with "through-and-through" pathways surrounded by drainage foam. Large curved hemostats were used to direct the soft drainage tubes from one incision to the other, following which the foam is packed into the incisions and externally over the infected area as well. This produces a foam drainage pathway with an overall seal achieved with an adhesive film covering. Again, the surgical techniques employed rely on blunt instruments to create drainage pathways followed by insertion of the soft drainage foam and tubes.

Broadly, there is a potential bio-incompatibility between many of the existing drainage tools adapted from use in other parts of the body, and infections of the facial spaces around and behind complex vascular structures. In order to support the recent trends towards negative wound pressure therapy in maxillofacial surgeries, there is a clear need for a novel and specialized drainage tool, the design of which the remainder of this paper addresses.

\section{Proposed Novel Drainage Tool for Facial Spaces}

In recognizing a lack of specialist drainage tools for the decompression of facial spaces, it is also important to recognize the unique technical and practical challenges posed by the complex vascular and nervous structures located within the head and neck. ${ }^{25}$ Whilst vacuum assisted drainage has been adopted in other regions of the body, previous design of the drainage tools to be inserted in corpi have featured a solid sponge, initially cut to size and placed within the area to be drained. A tube with one end connected to the vacuum is then inserted to meet one face of the solid sponge. This is advantageous when the region being drained must continuously contract, ie, draining an abscess where the lining will collapse and shrink, as the sponge can be withdrawn and resized. ${ }^{23}$ However, this is not well suited to draining facial spaces as there is typically less volumetric contraction of the infected space and the solid sponge end cannot easily be driven to reach the infected space. ${ }^{25}$

When assessing the biocompatibility of an infection draining tool for facial spaces, the critical design consideration is the ability of the tool to reach the infected space without damaging the surrounding structures. Thus, the instrument's design must focus on and optimize its relative flexibility or stiffness.

The novel instrument design proposed in this paper is illustrated in Figure 3. The unique design aspect is the combination of a narrowed portion of the drainage tube with a sleeved, rather than solid, sponge. The narrowed length of the drainage tube features pores to promote even drainage of the infected space and reduce the likelihood of blockages - an advantage over existing solutions with a planar drainage face joined to a solid sponge. The overall tool dimensions will be limited by the need for aesthetic wound healing. Whilst this theoretically also limits the drainage rate, the applied vacuum pressure and composition of the exudate will likely be controlling factors of the rate of drainage in practice. ${ }^{27}$

By combining the drainage tube with a sleeve sponge, the critical design variables become the drainage tube and sponge diameter and their respective thicknesses. In this paper, it will be demonstrated that variations of these dimensions within practical limits can result in significant variations of the radial and axial stiffness of the proposed drainage tool. Optimization of the tool design can thus achieve biocompatibility, in terms of stiffness, between the tool and the sensitive vascular and nervous structures of facial spaces addressing the gap within the existing solution landscape.

\section{Virtual Prototyping and Structural Analysis}

To demonstrate the versatility of the proposed design, the tool was modelled and analysed using the three-dimensional computer-aided design software 

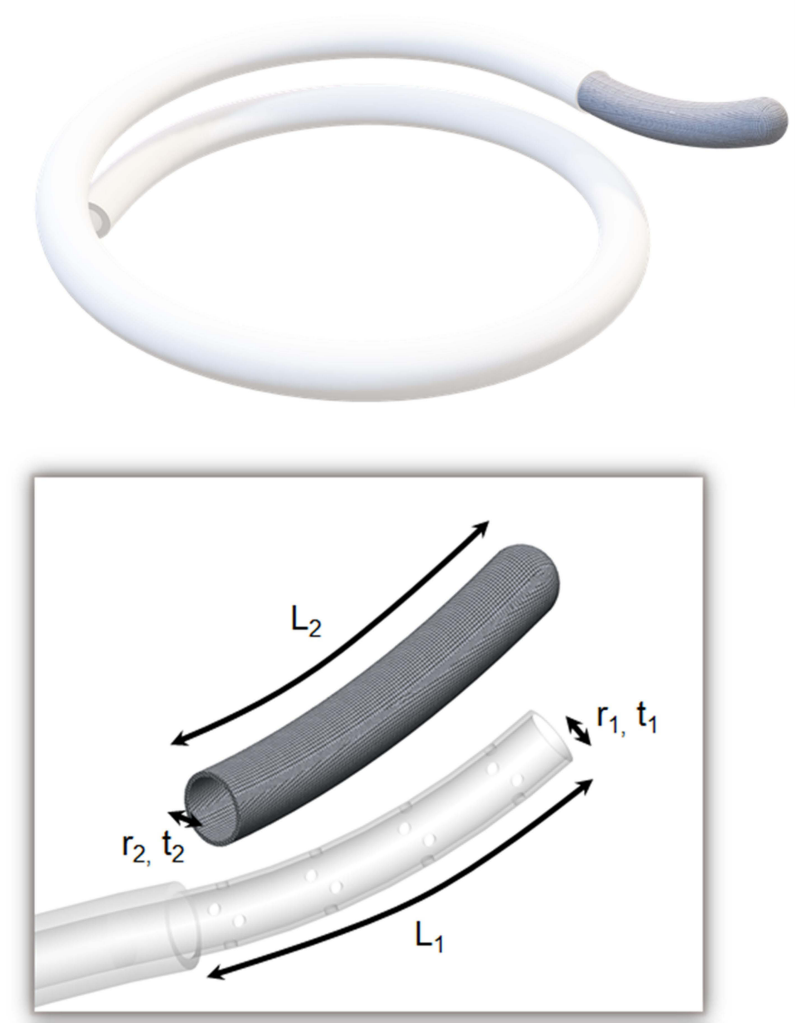

Figure 3 Novel drainage device for facial spaces.

SolidWorks. The simulation package uses the Finite Element method to predict deformations of the model in response to applied loads or stresses. ${ }^{28}$ The results from such a "virtual prototyping" design stage can be invaluable in investigating and verifying the design of a proposed surgical tool prior to in-vivo trials.

In this study, the response to varying the design dimensions will be contextualized with respect to a "base case", featuring the dimensions detailed in Table 1. Table 1 also shows the linear elastic material properties assigned to the various components of the instrument.

In Figure 4, the finite element model of the base case is shown. In addition to the three-dimensional mesh, the boundary conditions and external loadings are also shown. The far end of the silicone tubing modeled was fixed to prevent translation and rotation of that cross section. The sponge-tube interface features a bonded contact property. A normal pressure of $20 \mathrm{kPa}$ was applied to the sponge faces, ie, acting to compress the tool, in addition to a lateral pressure $20 \mathrm{kPa}$ that acts to bend the tool along its longer axis. Such stresses are of comparable magnitude to typical human blood pressure and lung pressures. ${ }^{29}$

Whilst the precise stress loading a drainage tool can experience in practice is difficult to ascertain, this is not a significant limitation to the virtual prototyping described in this paper for two reasons. Firstly, the boundary conditions and loading combinations have been chosen to illustrate how the proposed tool design can be adapted, in terms of variations to the tool dimensions, to achieve a range of overall stiffnesses. In addition to examining the absolute values predicted, which depend directly on the magnitude of loading applied, normalized results will be used in the cross comparison of different design cases. The magnitude of the stresses chosen is likely larger than would be experienced in practice. It was intentional to verify that major structural collapse of the tool would not occur for the typical material choices and loading. As the analyses performed are linear elastic, the optimizations of the design and cross comparison between cases can be scaled to other elastic cases with different properties. For example, if significantly smaller forces are experienced in practice, the tool could be constructed with a softer grade tubing and the relative effects of changes to the tool dimension presented in this paper could correctly be applied.

Following from Figure 4, the resulting predicted deformation of the base case (see Table 1) is presented in Figure 5. To facilitate cross comparison between cases with different geometries, the maximum axial and radial displacements of the end of the tool, ie, at the sponge tip, are extracted. The tip displacements indicate the overall tool stiffness, ie, combining the contribution from the inner tube and surrounding sponge, in the face of radial and axial loading. The relative magnitude of the displacements indicates the ease with which the tool will bend when navigating around structures in the facial spaces and compress when being pushed

Table I Details of Base Case

\begin{tabular}{|l|c|c|c|c|c|}
\hline Component & $\begin{array}{c}\text { Internal Diameter, Thickness and } \\
\text { Length } \mathbf{( m m )}\end{array}$ & Material & $\begin{array}{c}\text { Young's Modulus } \\
\mathbf{( G P a )}\end{array}$ & $\begin{array}{c}\text { Poisson } \\
\text { Ratio }\end{array}$ & $\begin{array}{c}\text { Density } \\
\left(\mathbf{k g} / \mathbf{m}^{\mathbf{3}}\right)\end{array}$ \\
\hline Drainage Tube & $2.50,0.75,20$ & Medical Grade Silicone Tubing & 1 & 0.49 & 1264.5 \\
Sponge & $4.00,2.00,24$ & Polyurethane Foam & 0.07 & 0.3 & 16.0 \\
\hline
\end{tabular}




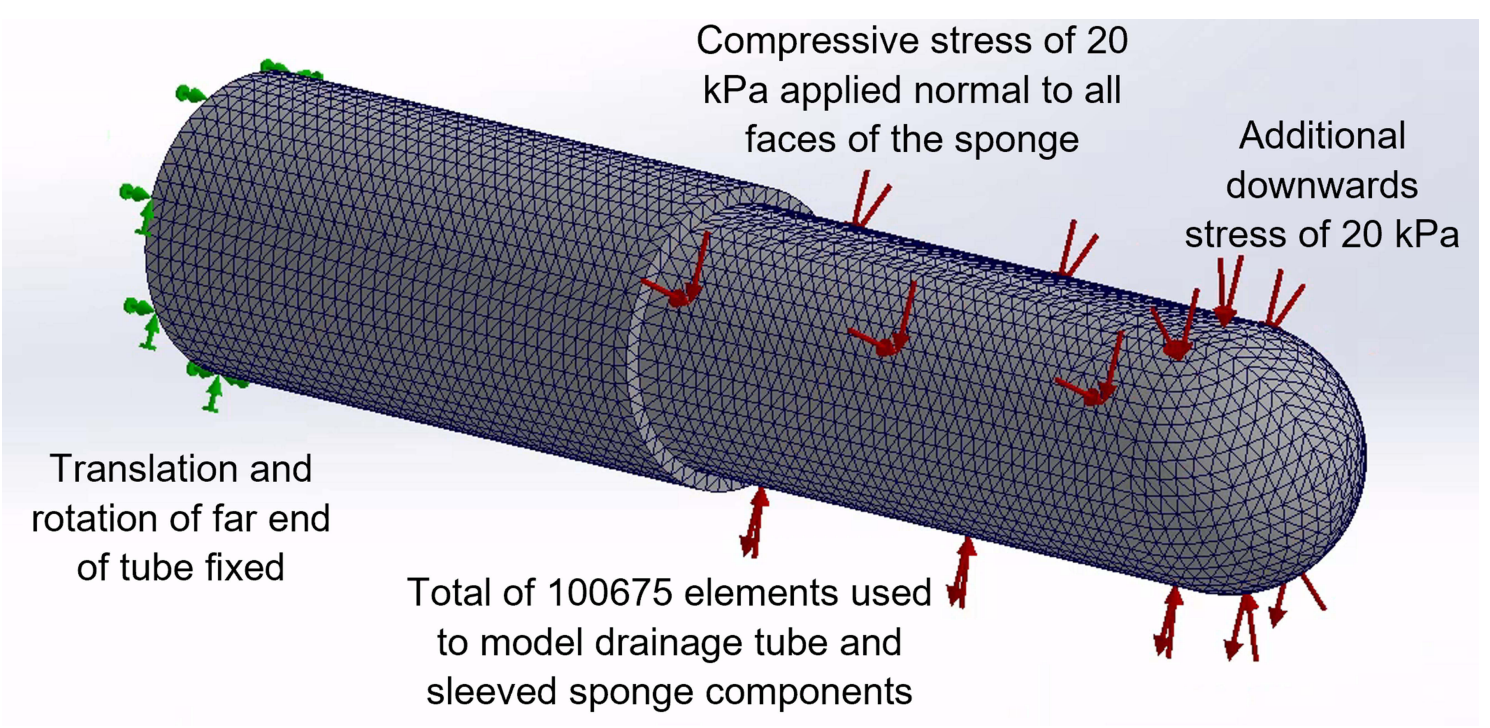

Figure 4 Boundary conditions and external loading applied during simulation of proposed drainage tool.

directly into an infected space. For the base case, the predicted values are $1.38 \mathrm{~mm}$ and $0.25 \mathrm{~mm}$ of radial deformation and axial compression, respectively.

The central hypothesis of the proposed design is that practical changes to the proposed tool dimensions can result in significant and useful variations of the tool's radial and axial stiffness. This is necessary to allow biocompatibility of the tool with the complex spaces located throughout the head and neck, which has been identified as a key factor for limited adoption of vacuum assisted drainage of infected facial spaces in the literature. ${ }^{2,25}$ To validate this, a design study of the proposed tool was undertaken with variations of critical dimensions of the base case, but keeping the tool length constant. Table 2 presents the range and intervals of dimensions considered to explore the tool design. In total, 64 unique design scenarios were analyzed with automated cycling of the tube and sponge dimensions using the SolidWorks Design Study feature. Illustrations of some of the design combinations studied are shown in Figure 6. To characterize the results, the radial and axial displacements induced by the applied stresses were extracted from each analysis. By maintaining constant applied stresses to the tools between cases, it should be noted that physically larger

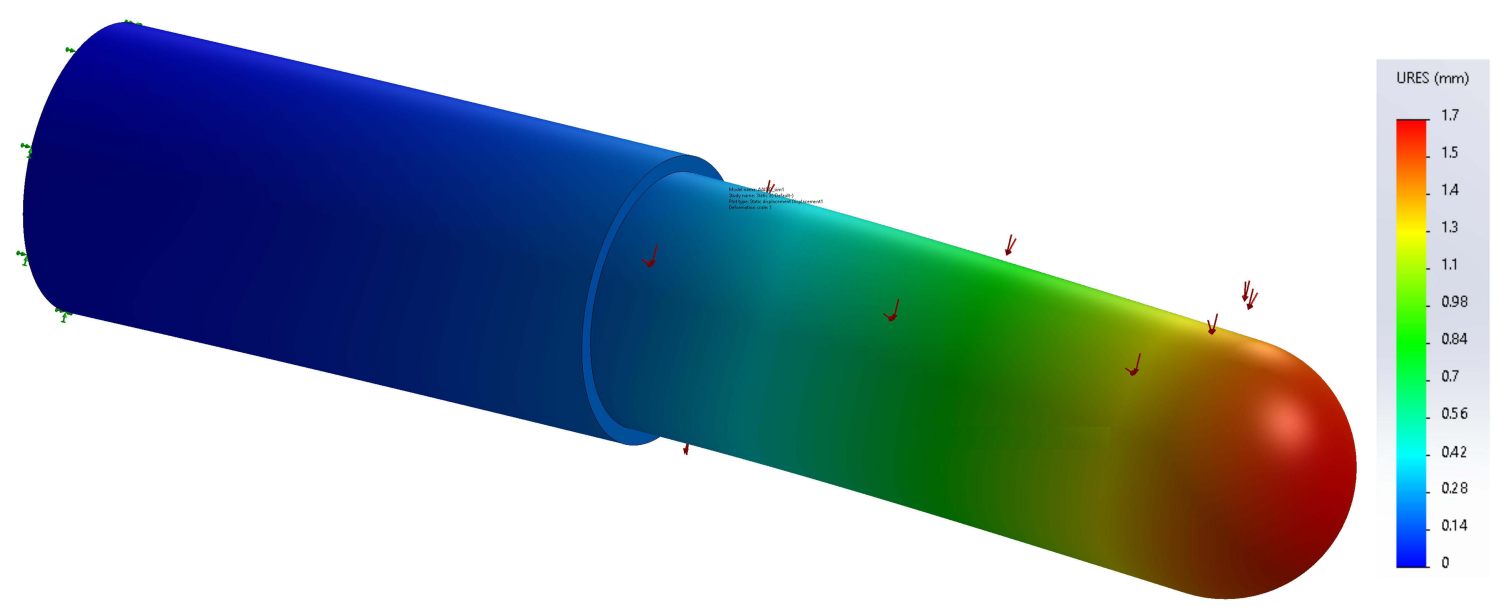

Figure 5 Predicted deformations for base case of proposed novel design tool. 
Table 2 Variations of Design Geometry Analyzed

\begin{tabular}{|l|c|c|}
\hline Dimension & $\begin{array}{c}\text { Base Case } \\
\text { Values } \\
\mathbf{( m m}\end{array}$ & $\begin{array}{c}\text { Range, Increment } \\
\text { of Variations (mm) }\end{array}$ \\
\hline Inner Diameter of Tube & 2.50 & $2.10-2.90,0.40$ \\
Outer Diameter of Tube/ & 4.00 & $3.00-5.00,1.00$ \\
Inner sponge Diameter & & $7.00-11.00,1.00$ \\
Outer Diameter of Sponge & 8.00 & \\
\hline
\end{tabular}

tools will experience greater loading overall, as may be expected in reality.

Figure 7 presents the results from the successfully completed parametric analyses for the tool design. Sets of three-dimensional surfaces corresponding to three families of design variants studied are presented. These were three inner tube diameters, each with changes to the sponge thickness and tube thickness. Studying Figure 7, it is apparent that the radial displacements are most sensitive to the tube thickness; this would be expected in light of the much larger material stiffness of the tube compared to the sponge. Over the dimensions studied the sponge thickness is also seen to influence the radial displacements, though the relationship depends on the tube diameter. This is a consequence of the greater load attracted by the increased surface area of the sponge opposing the contribution to the tool's radial stiffness by the increased sponge thickness. The sensitivity of the radial displacements to variations of the tube and sponge thickness is also clearly demonstrated to depend on the inner diameter of the tube, with the expected result that larger tube diameters permit less displacement. From a practical perspective, the overall tool dimension will be critical for aesthetic wound healing. Therefore, the ability to influence the tool's radial stiffness in response to horizontal loads with changes to either the tube diameter or sponge is a useful benefit of the design.

In Figure 7B the axial displacements predicted for the same design variations are presented. The relative importance of changes to the inner tube diameter and sponge thickness predicted is similar to that shown by Figure 7A. Increasing the tube thickness decreases the axial displacement for a given sponge thickness. The larger the sponge thickness, the larger the sponge dome at the front of the drainage tool, presenting a trade-off between increased sponge area resisting compression and softer material at the front of the tool that can be compressed.

To help generalize the trends predicted, Figure 8 presents the design study predictions normalized by the dimensions and results of the base case described in Table 1. Whilst the relative magnitude of the predictions is not independent of the dimensions of the base case selected, the range of dimensions studied reflects those that can be practically used for infections of the face and neck. In this context, with relatively minor changes to the drainage tube thickness and/or sponge thickness the radial and axial flexibility can be varied by approximately $300 \%$
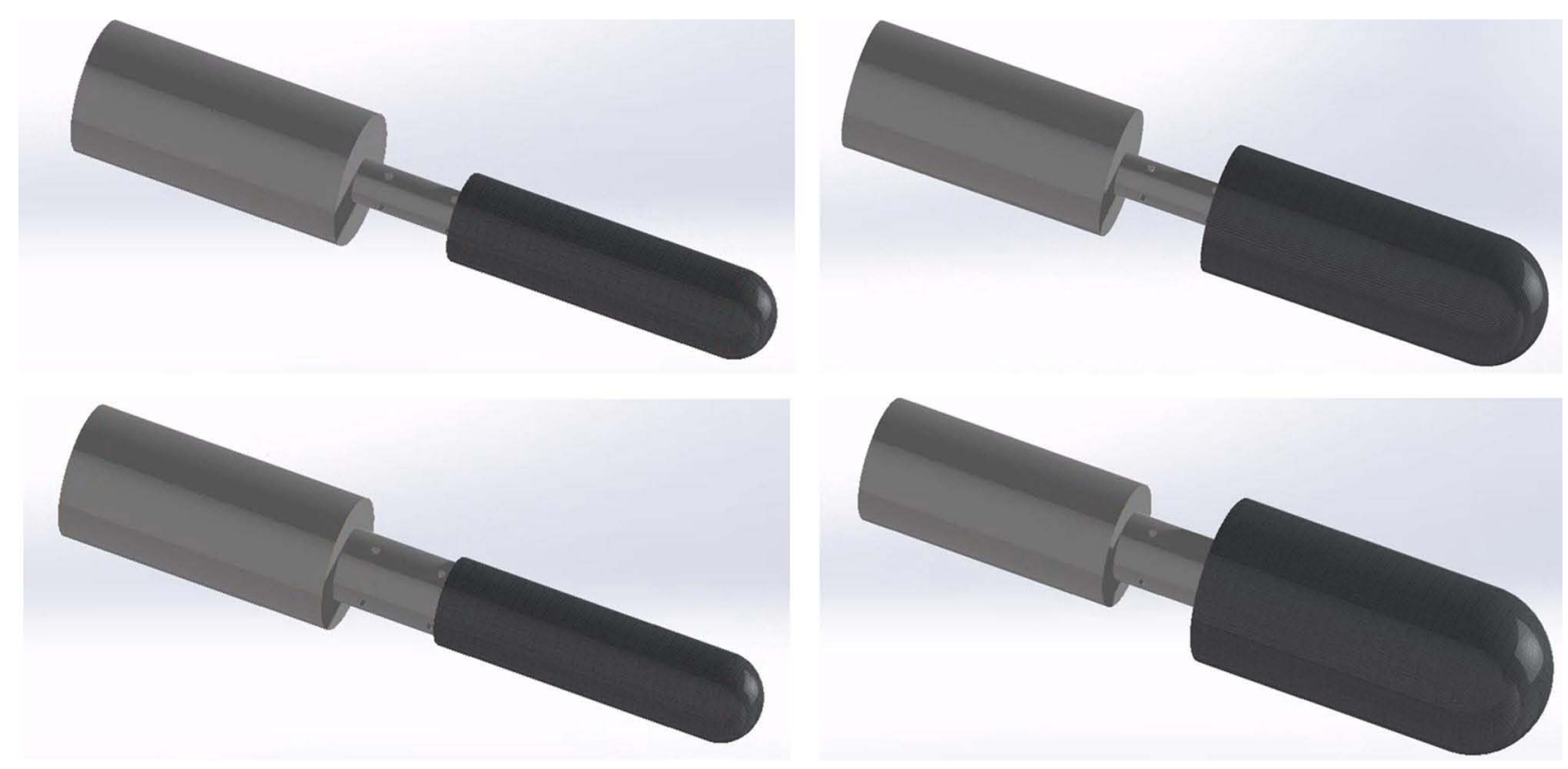

Figure 6 Examples of different drainage tool designs analysed with virtual prototyping, featuring variations to the inner tube and sponge dimensions. 


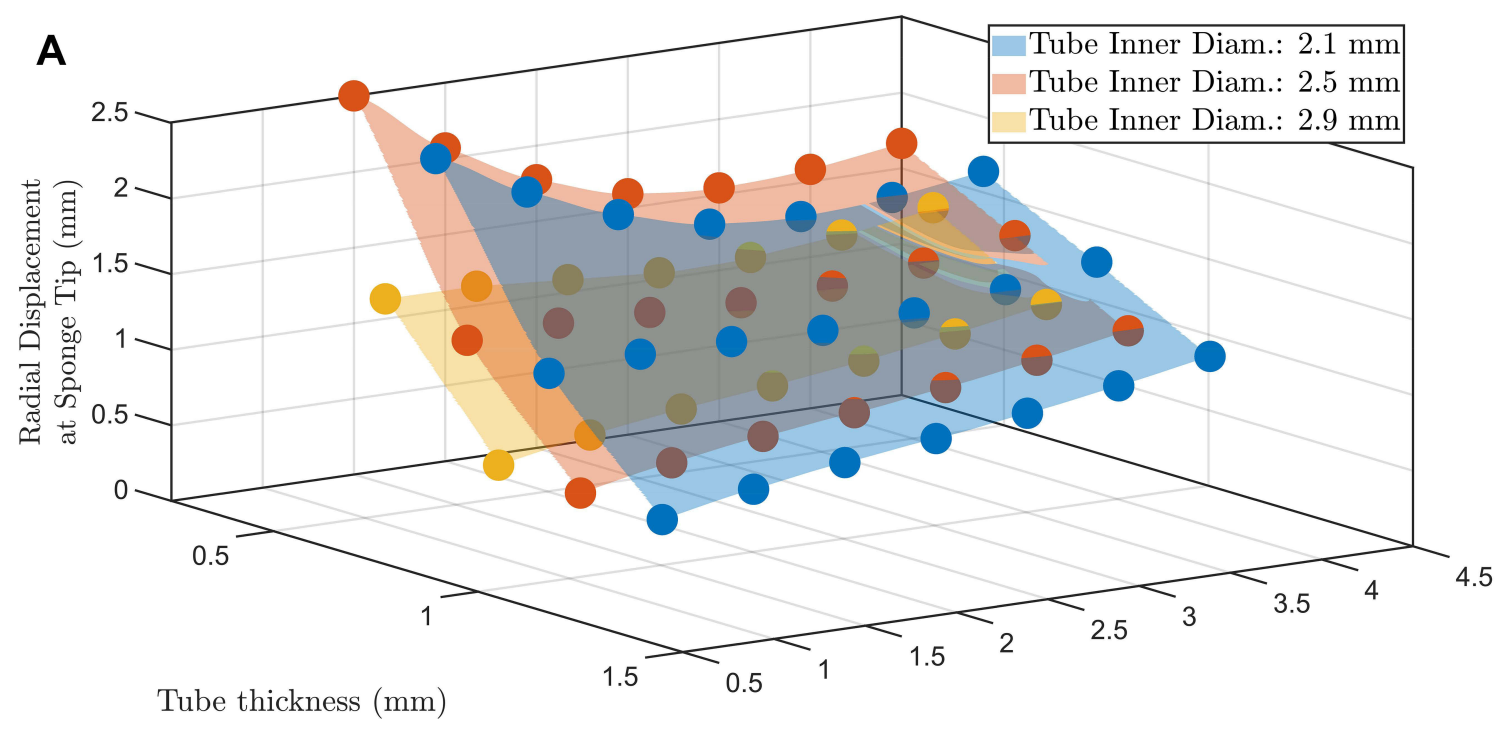

Sponge thickness $(\mathrm{mm})$

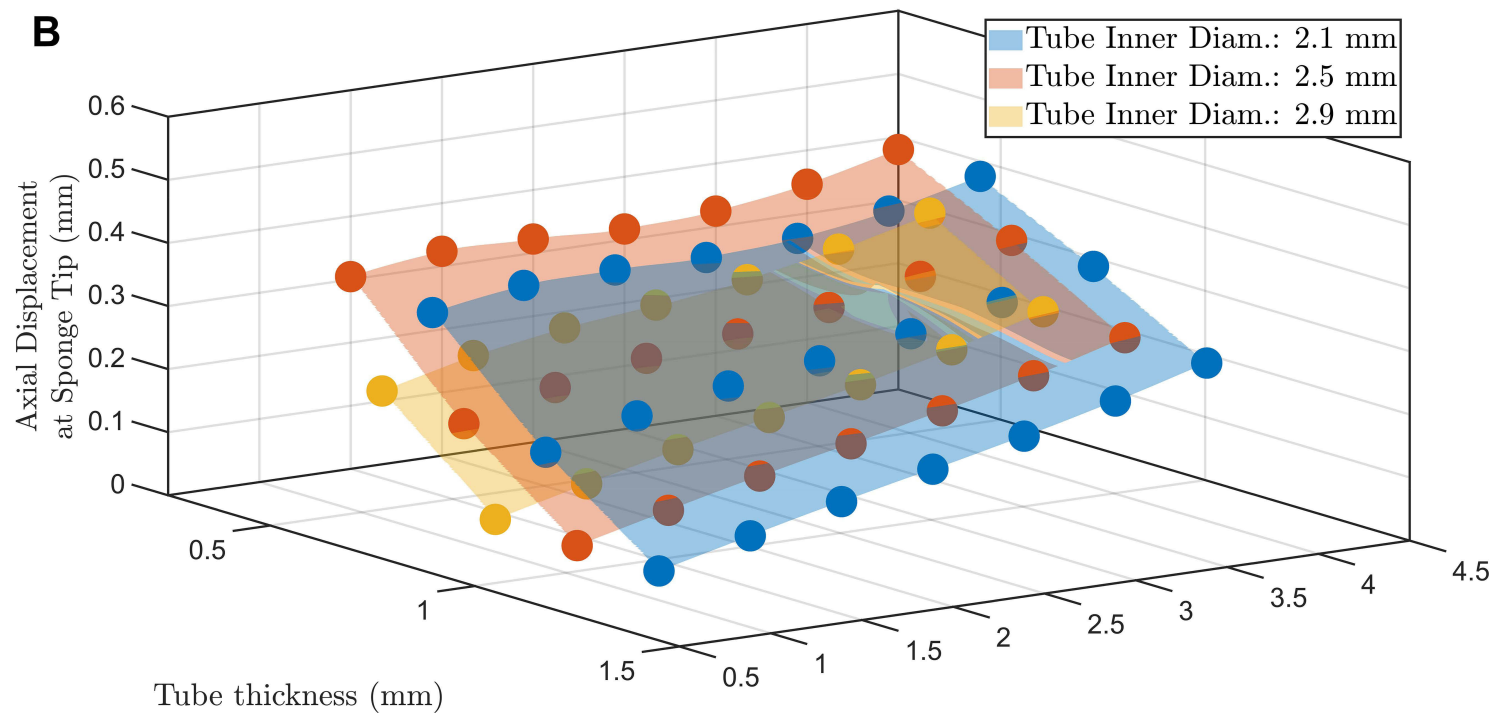

Sponge thickness $(\mathrm{mm})$

Figure 7 Variations of predicted tool deformations as a function of tube diameter, thickness and sponge thickness. (A) Effect on radial displacements. (B) Effect on axial compression.

and $340 \%$, respectively. These predictions include the coupled changes to the tool stiffness and loads attracted by changes to the design geometry. Ultimately, achieving biocompatibility between the drainage device stiffness and the complex structures of the face and neck is a driving factor for the adoption of modern vacuum assisted drainage systems for these applications. The present study demonstrates how the novel design concept of a drainage tube with reduced diameter and sleeved sponge can be sized, within practically useful limits, to achieve a range of overall stiffnesses.

\section{Concluding Remarks}

In this paper, the decompression of infected facial spaces has been considered. Previous literature evidences drawbacks to traditional incision and drainage procedures, including extended procedure times and patient discomfort. Whilst negative pressure wound therapy can address these disadvantages, the existing literature reveals its adoption to maxillofacial surgeries has been limited. This may be attributed to a lack of specialized drainage tools for this application. Specifically, there is a need for a small but sufficiently stiff drainage tool that may navigate 


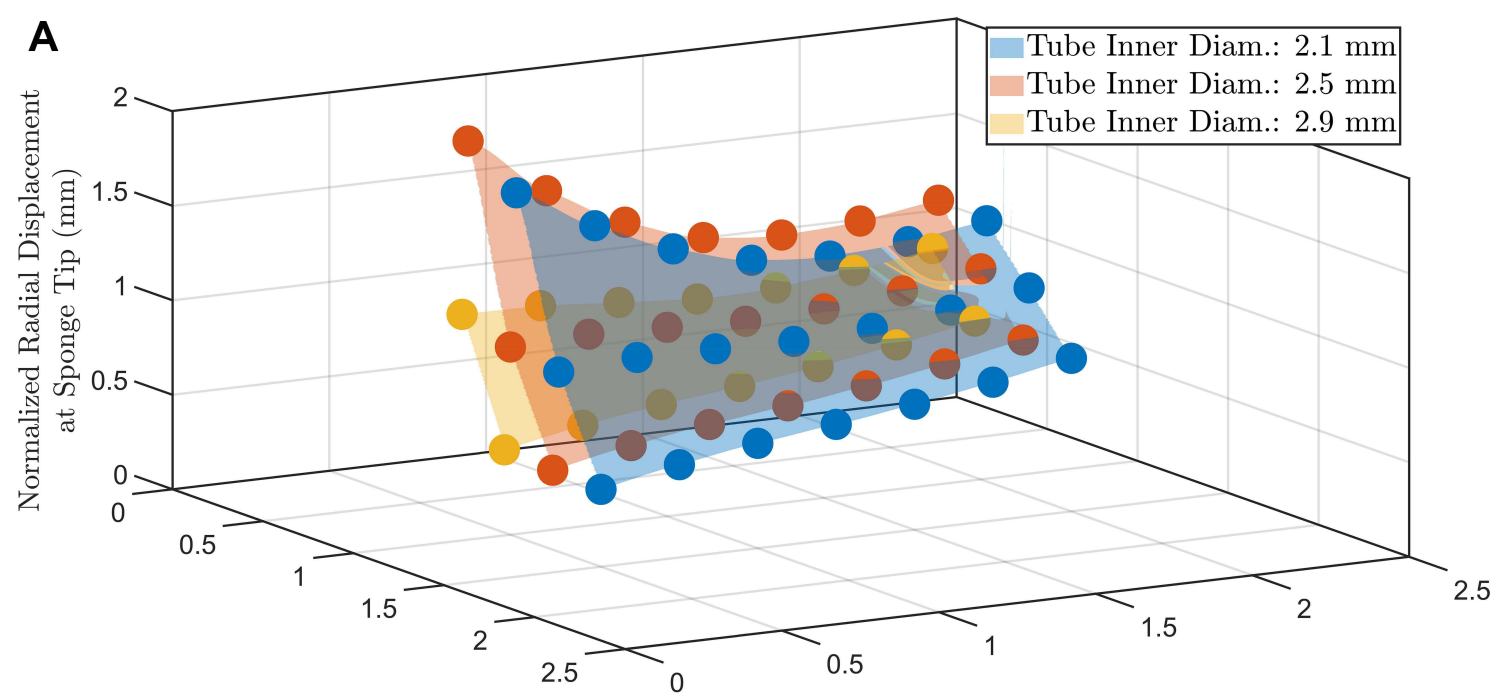

Normalized Tube thickness (mm)

Normalized Sponge thickness (mm)

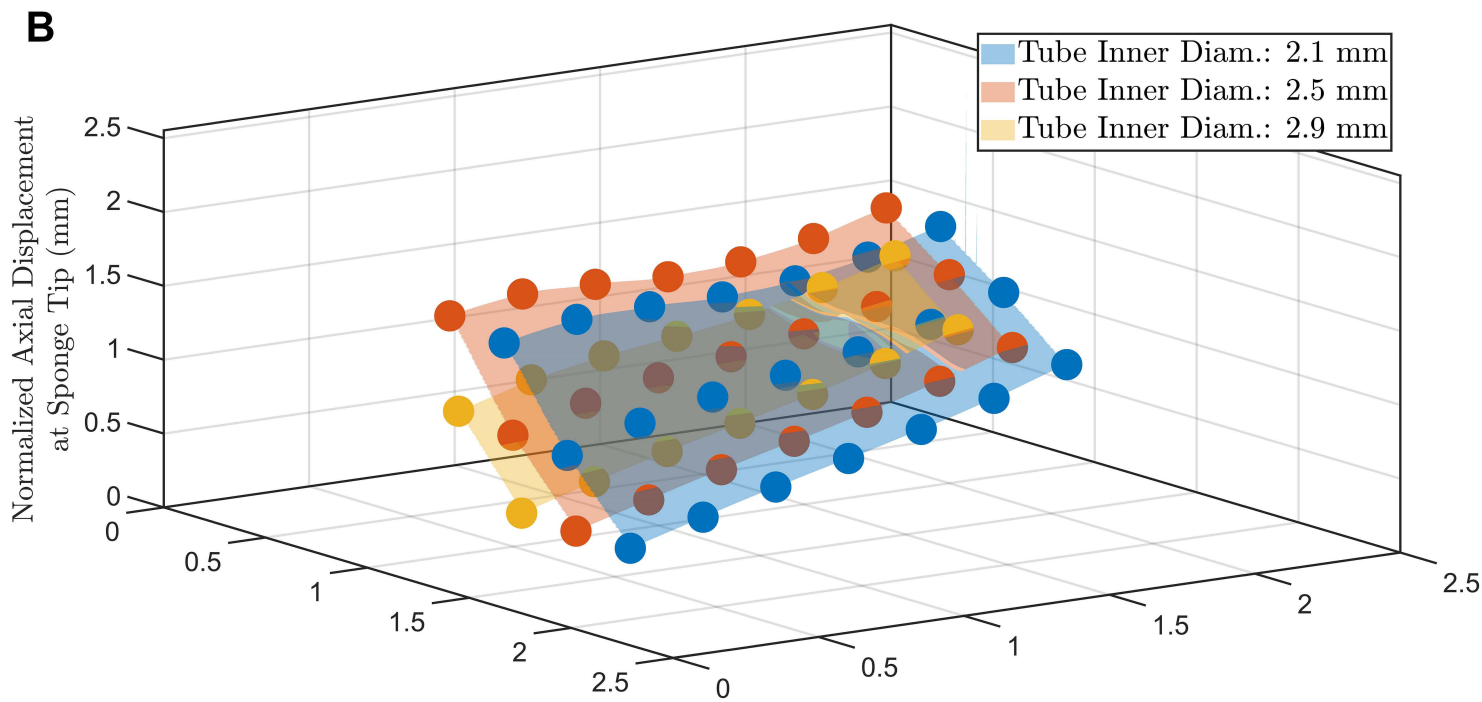

Normalized Tube thickness (mm)

Normalized Sponge thickness (mm)

Figure 8 Variations of predicted normalized tool deformations as a function of tube diameter, thickness and sponge thickness. (A) Effect on radial displacements normalized by base case. (B) Effect on axial compression normalized by base case.

around the complex structures in the head and neck. In this work, a novel drainage tool whose design focuses on biocompatibility in terms of the overall axial and radial stiffness is proposed. A sleeved sponge, in contrast to a traditionally solid sponge that is used in other parts of the body, is suggested in combination with a perforated inner drainage tube to meet many of the design needs of the head and neck.

As a first step in exploring the design, virtual prototyping and structural analyses of the concept were performed. Simplifications to the material constitutive models (linear-elastic) and interface between the sponge and tube (bonded) were made to facilitate efficient predictions of the axial and radial displacements of the cases analysed using a 3D Finite Element model. Fixed compressive and radial stresses were applied to 64 independent cases of tool dimensions based on the proposed concept. This allowed design variations of the tube and sponge thickness to be analysed. The proposed instrument concept was predicted to exhibit significant variations to its overall stiffness dependent on small and practically realizable changes to the inner tube and sponge dimensions. It is noted that 
precise prediction of large deformations of porous materials, such as the sponge, is particularly challenging. However, as the predicted sleeved sponge deformations were largely governed by the internal tubing displacement, this is not considered a significant limitation of the analyses conducted and broad conclusions reached. This study thus serves as an initial verification of an improved drainage tool design compared to the existing solutions, and highlights the key design variables to ensure biocompatibility of the tool in terms of stiffness. Ultimately, this can help address the limited adoption of negative pressure wound therapy for maxillofacial applications.

Future work should focus on the drainage rates the design can theoretically and practically achieve in-vivo, ${ }^{27}$ and on identifying a narrowed range of tool stiffnesses that can meet the varied demands of surgical procedures to the head and neck. More broadly, it is anticipated that the proposed sleeved sponge concept, which through practical changes to the individual component dimensions can offer the surgeon a variety of stiffnesses, could see wider adoption in decompression procedures around the body.

\section{Disclosure}

The authors report no conflicts of interest in this work.

\section{References}

1. Flynn TR. Surgical management of orofacial infections. Atlas Oral Maxillofac Surg Clin North Am. 2000;8(1):77-100. doi:10.1016/ S1061-3315(18)30043-X

2. Umezawa H, Matsutani T, Yokoshima K, Nakamizo M, Ogawa R. A novel tube-drainage technique of negative pressure wound therapy for fistulae after reconstructive surgery. Plast Reconstr Surg Glob Open. 2018;6(8):e1885. doi:10.1097/GOX.0000000000001885

3. Fleischmann W, Strecker W, Bombelli M, Kinzl L. Vacuum sealing as treatment of soft tissue damage in open fractures. Unfallchirurg. 1993;96(9):488-492.

4. Rosenthal EL, Blackwell KE, McGrew B, Carroll WR, Peters GE. Use of negative pressure dressings in head and neck reconstruction. Head Neck J Sci Spec Head Neck. 2005;27(11):970-975. doi:10.1002/hed.20265

5. Holland CS. The management of Ludwig's angina. Br J Oral Surg. 1975;13(2):153-159. doi:10.1016/0007-117X(75)90003-7

6. Umeda M, Minamikawa T, Komatsubara H, Shibuya Y, Yokoo S, Komori T. Necrotizing fasciitis caused by dental infection: a retrospective analysis of 9 cases and a review of the literature. Oral Surgery, Oral Med Oral Pathol Oral Radiol Endodontol. 2003;95(3):283-290. doi:10.1067/moe.2003.85

7. Zamiri B, Hashemi SB, Hashemi SH, Rafiee Z, Ehsani S. Prevalence of odontogenic deep head and neck spaces infection and its correlation with length of hospital stay. J Dent. 2012;23:54.

8. Eshghpour M, Sabouri M, Labafchi A, Shooshtari Z, Samieirad S. Maxillofacial infections: a 5-year assessment of the epidemiology and etiology in an Iranian population. J Maxillofac Oral Surg. 2021;2:1-8.

9. Lemonick DM. Ludwig's angina: diagnosis and treatment. Hosp Physician. 2002;38(7):31-37.
10. Ahmad M. Procedure: incision and drainage of a superficial abscess. J Pak Med Assoc. 1984;34(9):286-289.

11. Durai R, Ng PCH. Surgical vacuum drains: types, uses, and complications. AORN J. 2010;91(2):266-274. doi:10.1016/j.aorn. 2009.09.024

12. Fitch MT, Manthey DE, McGinnis HD, Nicks BA, Pariyadath M. Abscess incision and drainage. $N$ Engl $J$ Med. 2007;357(19):e20. doi:10.1056/NEJMvcm071319

13. Peters ES, Fong B, Wormuth DW, Sonis ST. Risk factors affecting hospital length of stay in patients with odontogenic maxillofacial infections. J Oral Maxillofac Surg. 1996;54(12):1386-1391. doi:10.1016/S0278-2391(96)90249-9

14. Vithal P, Das CP, Mohanty D, Rout MR. Ludwig's angina, treatment protocol and observation at a tertiary care hospital. Indian J Appl Res. 2017;7(3):100-101.

15. Miller C. The history of negative pressure wound therapy (NPWT): from "lip service" to the modern vacuum system. $\mathrm{J} \mathrm{Am} \mathrm{Coll} \mathrm{Clin}$ Wound Spec. 2012;4(3):61-62. doi:10.1016/j.jccw.2013.11.002

16. Horch RE. Incisional negative pressure wound therapy for high-risk wounds. J Wound Care. 2015;24(Sup4b):21-28. doi:10.12968/jowc. 2015.24.Sup4b.21

17. Lin $Y$, Wang $H$, Zhang X. Application of vacuum sealing drainage in oral and maxillofacial surgery. Biomed Res. 2018;29(3). doi:10.4066/ biomedicalresearch.29-17-878

18. Stannard JP, Robinson JT, Anderson ER, McGwin G Jr, Volgas DA, Alonso JE. Negative pressure wound therapy to treat hematomas and surgical incisions following high-energy trauma. $J$ Trauma Acute Care Surg. 2006;60(6):1301-1306. doi:10.1097/01.ta.0000195996.73186.2e

19. Argenta LC, Morykwas MJ. Vacuum-assisted closure: a new method for wound control and treatment: clinical experience. Ann Plast Surg. 1997;38(6):563-577. doi:10.1097/00000637-199706000-00002

20. Gallo O, Deganello A, Meccariello G, Spina R, Peris A. Vacuum-assisted closure for managing neck abscesses involving the mediastinum. Laryngoscope. 2012;122(4):785-788. doi:10.1002/lary.22403

21. Krug E, Berg L, Lee C, et al. Evidence-based recommendations for the use of negative pressure wound therapy in traumatic wounds and reconstructive surgery: steps towards an international consensus. Injury. 2011;42:S1-S12. doi:10.1016/S0020-1383(11)00041-6

22. Gregor S, Maegele M, Sauerland S, Krahn JF, Peinemann F, Lange S. Negative pressure wound therapy: a vacuum of evidence? Arch Surg. 2008;143(2):189-196. doi:10.1001/ archsurg.2007.54

23. Arezzo A, Miegge A, Garbarini A, Morino M. Endoluminal vacuum therapy for anastomotic leaks after rectal surgery. Tech Coloproctol. 2010;14(3):279-281. doi:10.1007/s10151-010-0569-0

24. Schuster R, Moradzadeh A, Waxman K. The use of vacuum-assisted closure therapy for the treatment of a large infected facial wound. $\mathrm{Am}$ Surg. 2006;72(2):129-131. doi:10.1177/000313480607200206

25. Cao J, Liu Z, Ma D, Shen S, Wang X. Modified usage of negative pressure wound therapy for the management of severe deep fascial space infections in the head and neck. Infect Drug Resist. 2020;13:781. doi:10.2147/IDR.S243794

26. Loaec E, Vaillant P-Y, Bonne L, Marianowski R. Negative-pressure wound therapy for the treatment of pharyngocutaneous fistula. Eur Ann Otorhinolaryngol Head Neck Dis. 2014;131(6):351-355. doi:10.1016/j.anorl.2013.12.001

27. Khansa I, Khansa L, Meyerson J, Janis JE. Optimal use of surgical drains: evidence-based strategies. Plast Reconstr Surg. 2018;141 (6):1542-1549. doi:10.1097/PRS.0000000000004413

28. Shih RH. Finite Element Analysis Using SolidWorks Simulation. SDC publications; 2014.

29. Orders of magnitude (pressure). Available from: https://en.wikipedia. org/wiki/Orders_of_magnitude_(pressure). Accessed April 23, 2020. 


\section{Publish your work in this journal}

Medical Devices: Evidence and Research is an international, peerreviewed, open access journal that focuses on the evidence, technology, research, and expert opinion supporting the use and application of medical devices in the diagnosis, monitoring, treatment and management of clinical conditions and physiological processes. The identification of novel devices and optimal use of existing devices which will lead to improved clinical outcomes and more effective patient management and safety is a key feature of the journal. The manuscript management system is completely online and includes a very quick and fair peer-review system. Visit http:// www.dovepress.com/testimonials.php to read real quotes from published authors.

Submit your manuscript here: https://www.dovepress.com/medical-devices-evidence-and-research-journal 